\title{
Bitemporal ultra-brief pulse electroconvulsive therapy for the treatment of neuroleptic malignant syndrome in a first psychotic episode: a case report
}

\author{
Eletroconvulsoterapia bitemporal com pulso ultra-breve para o tratamento de \\ síndrome neuroléptica maligna em um primeiro episódio psicótico: um relato \\ de caso
}

The neuroleptic malignant syndrome (NMS) is a severe clinical condition, triggered by an idiosyncratic toxic response to drugs used in medical practice, mainly antipsychotics. Studies have found mortality rates of 10 to $20 \% .^{1}$ We report a case of NMS including signs of catatonia in a patient undergoing his first episode of psychosis, in which remission was achieved using electroconvulsive therapy (ECT).

A 31-year-old man was admitted to our psychiatric emergency unit presenting with psychomotor agitation, withdrawal, uncooperativeness, stereotypy, and alternating perseveration with mutism. It was impossible to communicate with him. Three weeks before admission, he had become paranoid and had some auditory hallucinations. During the week before admission he started taking $1 \mathrm{mg}$ risperidone per day. He has comorbid type 1 diabetes mellitus and no other diagnoses, and his only family history is an aunt with Schizophrenia. Due to severe agitation, he was given $10 \mathrm{mg}$ of intramuscular (IM) olanzapine, which was ineffective, and 60 minutes later $5 \mathrm{mg}$ haloperidol IM plus $50 \mathrm{mg}$ promethazine IM. He had low fever $\left(38^{\circ} \mathrm{C}\right)$, and the main abnormal results detected by the initial laboratory tests were as follows: leukocyte count 27,540 $/ \mathrm{mm}^{3}$, with $11 \%$ bands, and lactate dehydrogenase (LDH) $266 \mathrm{U} / \mathrm{L}$ (81-234 U/L). Results of a second battery of laboratory tests, conducted within 24 hours of the first tests were as follows: creatinine $2.0 \mathrm{mg} / \mathrm{dL}$, sodium $150 \mathrm{mmol} / \mathrm{L}$, potassium $5.8 \mathrm{mmol} / \mathrm{L}$, aspartate transaminase (AST) $163 \mathrm{U} / \mathrm{L}$, lactate $9.7 \mathrm{mmol} / \mathrm{L}$, and creatine phosphokinase (CPK) 10,351 UI/L. Additional tests, to rule out infection, found no significant abnormalities (blood and urine cultures, qualitative urinalysis, and chest $\mathrm{X}$-ray) and a physical examination was normal. The ECG only showed sinus tachycardia. Once NMS had been suspected, antipsychotics were discontinued and oral lorazepam or IM midazolam were initiated (depending on patient cooperation). After the first $24 \mathrm{~h}$, up to the 6 th day since admission, his behavior alternated between calm and agitated, he presented low fever, tachypnea, tachycardia, and hypertensive peaks (up to $160 \times 100 \mathrm{mmHg}$ ), and was managed with supportive measures. Given the strong suspicion of NMS, and persistence of the condition, the patient was treated with ECT. This was performed using a spECTrum 4000M, bitemporal electrodes, ultra-brief pulse, and an initial charge of $100.1 \mathrm{mC}$, which was ineffective. The second stimulus used a charge of $116.7 \mathrm{mC}$, causing a motor crisis of 20 seconds, without complications. After the first session of ECT, the patient exhibited a rapid and dramatic response; vital signs normalized, there was remission from agitation, psychosis, and stereotypies, and laboratory test results improved gradually.

The patient described here presented in a catatonic condition after use of neuroleptics, in line with the hypothesis that NMS is a neuroleptic-induced malignant catatonia (MC). ${ }^{2}$ In cases in which this diagnostic hypothesis is suspected, the first action that should be taken is to withdraw antipsychotics and start benzodiazepines. ${ }^{3}$ If these medications do not work, ECT is the best option, irrespective of the etiology of catatonia. This decision must be taken quickly, because of the clinical risk of NMS, which is associated with high mortality. ${ }^{4}$ The success achieved in this case of NMS supports the effectiveness of this procedure. We suggest that psychiatric referral services should consider ECT as a powerful tool for management of cases of both NMS and $\mathrm{MC}$. 
Kathy Aleixo Marcolin, ${ }^{1}$ Cazuza Oliveira Rodrigues, ${ }^{1}$ Tissiana Maria Falcão Muller, ${ }^{1}$ Felipe Salles de Salles, ${ }^{1}$ Vitor Calegaro, ${ }^{2}$ Angelo Batista Miralha da Cunha ${ }^{2}$

1 Departamento de Neuropsiquiatria, Universidade Federal de Santa Maria (UFSM), Santa Maria, RS, Brazil. ${ }^{2}$ Departamento de Neuropsiquiatria, UFSM, Santa Maria, RS, Brazil.

\section{References}

1. Shalev A, Hermesh $H$, Munitz $H$. Mortality from neuroleptic malignant syndrome. J Clin Psychiatry. 1989;50:18-25.

2. Luchini F1, Lattanzi L, Bartolommei N, Cosentino L, Litta A, Kansky C, et al. Catatonia and neuroleptic malignant syndrome: two disorders on a same spectrum? Four case reports. J Nerv Ment Dis. 2013;201:36-42.

3. Lee JW. Neuroleptic-induced catatonia: clinical presentation, response to benzodiazepines, and relationship to neuroleptic malignant syndrome. J Clin Psychopharmacol. 2010;30:3-10.

4. Zisselman $M H$, Jaffe RL. ECT in the treatment of a patient with catatonia: consent and complications. Am J Psychiatry. 2010;167:127-32.

\section{Correspondence}

Kathy Aleixo Marcolin

Hospital Universitário de Santa Maria

Av. Roraima, 1000, Camobi

97105-900 - Santa Maria, RS - Brazil

E-mail: aleixo.kathy@gmail.com

Submitted Aug 16 2015, accepted for publication Jul 132016. No conflicts of interest declared concerning the publication of this article.

Financial support: none.

Suggested citation: Marcolin KA, Rodrigues CO, Muller TM, de Salles FS, Calegaro V, da Cunha AB. Bitemporal ultra-brief pulse electroconvulsive therapy for the treatment of neuroleptic malignant syndrome in a first psychotic episode: a case report [letter]. Trends Psychiatry Psychother. 2017;39(1):62-63. http:// dx.doi.org/10.1590/2237-6089-2015-0045 